\title{
A Demographic Approach to Evaluate the Development of Tourism Industry of Mainland China
}

\section{Junjian Lin}

School of Management, Jinan University, Guangzhou, China

Email: Junjian_Lin@163.com

How to cite this paper: Lin, J.J. (2018) A Demographic Approach to Evaluate the Development of Tourism Industry of Mainland China. Open Journal of Social Sciences, 6, 33-49.

https://doi.org/10.4236/jss.2018.63004

Received: February 13, 2018

Accepted: March 13, 2018

Published: March 16, 2018

Copyright $\odot 2018$ by author and Scientific Research Publishing Inc. This work is licensed under the Creative Commons Attribution International License (CC BY 4.0).

http://creativecommons.org/licenses/by/4.0/

\section{(c) (i) Open Access}

\begin{abstract}
As the tourism industry shows a noticeable impact on the social and economic environment in China, it is essential to study how this industry has influenced the country. This paper discusses the relationship between some of the features of demographics and the development of tourism in China in recent years to evaluate the development of tourism in China. A province-level panel dataset is constructed from the related statistical yearbook to be applied to a pooled, fixed effect and random effect model respectively to check the correlation between the demographics features and development of tourism. As the result shows, the fast development of tourism has a highly positive correlation with urbanization process in China. However, the rapid growth in tourism seems to be negatively correlated with local total fertility rates. And to the side of mortality rate, the rise of tourism sometimes even has a significant adverse effect, which means the development of the tourism industry will have the impact for increasing mortality of that province. Those exciting results show that the tourism development in mainland China in the past few years, especially after the global financial crisis in 2008 , could be quite challenging to the sustainable development of the Chinese economy. The economic structure of the industry of tourism in China still needs to be improved to achieve a better goal to benefit the nation with a long-term goal.
\end{abstract}

\section{Keywords}

Tourism Development, Urbanization, Demographic Evaluation, China, Scale Economy

\section{Introduction}

It is essential to understand the development of tourism industry of a country. 
As pointed out by the World Tourism Organization (UNWTO) [1], tourism is an economic and social phenomenon which is a key driver for the increasing economic growth in the world. In the meanwhile, tourism helps to provide more employment in many sectors, such as hotel industry, airline transportation, travel insurance, and telecommunications sectors. According to China National Tourism Administration [2], the overall contribution of tourism to GDP in 2017 was RMB 9.13 trillion, accounting for $11.04 \%$ of the total GDP. 79.9 million people worked in the tourism industry directly or indirectly, accounting for $10.28 \%$ of China's working population. The growth of the number of international tourists becomes one of the most prominent features in the global tourism. According to UNWTO statistics, the international tourist arrivals grew by $4.6 \%$ in 2015 to 1184 million and brought 1.5 trillion U.S. dollars in export earnings. Mainland China (hereafter, referred to mainland China, not including Hong Kong, Macaw and Taiwan), the largest developing country in the world with one of the highest GDP growth of the world in the recent decades, has also experienced this rapid upward sloping tourism growth with more than 3 billion of domestic travelling trips of 2013 than that of 1996 [3].

However, it is ambiguous to see if the industry has generated purely benefit of the economy in China or produced negative externalities to the society as well. On one hand, it indeed has generated more GDP and more employment positions in the related fields with larger inflows of tourism both from domestic and international countries or regions in mainland China over the past few decades. Zhao et al. estimated from their quantitative analysis that the tourism industry has increased employment directly in China by using the panel data by province-level from 1999-2014 [4]. On the other hand, there is always argument in the literatures about the negative impacts of the development of tourism, as shown in the study [5], to the economic costs and negative socio-psychological impacts. However, this has not been stressed so much in mainland China before. In another word, it is time to investigate the impacts of the development of tourism industry to give the evaluation about whether it has more positive effects or more negative effects to the society.

There are more reasons to choose mainland China, which is the second largest economy of the world with the largest population group, as the targets to carry out this study are following. One of the recent but important social phenomena in mainland China is the low total fertility rate, which has been lasting for many years after the famous "One-child Policy" starting from the 1970s of the central government of China. As the Department of Social Affairs of the United Nations pointed out [6], within seven years, the size of the population of China will be surpassed by the size of the population of India. Lower fertility rate also brought concerns about the aging population structure as pointed by Feng et al. in 2013 [7]. The government started to relax the restriction of the one-child policy and carried out two-child policy in China in recent years. However, the reform of the fertility policy does not cause the enthusiasm of the residents for giving more 
births to the family. Surveys and data show that the two-child new fertility policy fails to increase the speed of gaining of the national population [8]. The reasons behind the phenomenon that why people do not want to make the new policy work could be complicated and mysterious, but the results of the little effect of the new fertility policy will not solve the problem that the shortage of the labor of China. The discussion from any related aspects that could explain the puzzle would be a break-through not only in the literature but also to the practical parts of the goal of sustainable development of the country. Therefore, it is essential to study any economic sector, which could affect the amount of employment and the increase of the net population growth in China.

In this sense, this paper strives to combine the two big aspects of the economy of China: tourism industry and demographic features to give the evaluation of the development of the tourism industry in China. This study is also among the first paper attempts to evaluate how the tourism industry affects the society from the demographic aspects: urbanization (internal migration inflows), total fertility, mortality mainly after the 2008 global financial crisis to see the correlation. A panel-dataset structure is used to conduct an empirical regression model for the study of this topic. In the following section, related literatures will be reviewed. In the third section, this paper will introduce the constructed dataset and the associated variables for this research. In the fourth section, economic models will be set up from both structural sides and empirical sides to conduct the analysis of the relationship of the tourism industry and demographic features in China from 2007-2013. Finally, this paper gives the conclusion of the study.

\section{Literature Review}

There is plenty of research to investigate the relationship between tourism and demography. For example, in the book of Smith, Karen, et al. in 2011 [9], they discussed that the demographic pattern will shape and change the demand and supply of the tourism, which will further change the pattern of an economy. Another paper from Casagrande in 2016 [10] argued about the challenges of the demography brought by the nearby tourism industry. It was argued in the paper that the influx of the tourists brought difficulty in protecting the local heritage and environment in Venice. However, they did not include the aspects of the inflows of the tourists, the expenditures of the international tourists, together with the revenues generated by the tourism industry to discuss both the positive effects and negative effects. Also, they were focusing on either the entire trend of the world or some cases of the development countries in their studies.

Mainland China is the largest developing country in this world with the largest population. However, in Haft's book, he mentioned that there is hidden truth about the China's economy miracle, which could make this country never catch up with the US economy [11]. Yet it would be interesting to check how the tourism industry has developed during the period of rapid economic growth of China in the past. To evaluate the aspect of the tourism development in China, re- 
searchers also followed the relationship of the tourism industry and demographic features in China, especially urbanization in China, to carry out the study. For example, the paper written by Luo, Qiu and Lam in 2014 studied the urbanization impacts on tourism development in four regions Guangdong province [12]. The paper also provides the panel data study of Guangdong province from 1996 to 2011. However, there is lack of the analysis of the tourism industry with fertility and mortality status in China for the current period. Why would we care about this relationship? First, we would like to know if the development of tourism industry could be the shock, especially the inflows of the international tourists could impact the low fertility decisions made by each family. Evidence by Jones and Schoonbroodt in their 2010 paper showed [13] that historically the fertility rates of the United States were positively correlated with the productivity by using the quantitative calibration of a dynamic model. Following this logic, if one can show that the productivity of the tourism industry can at least have the same fluctuation with the fertility, it means that in the necessary conditions, the development of the tourism industry could be accessed with the sign of the correlation inversely. Second, the mortality rate is the weighted average of different groups of populations, which are usually grouped by infant group, under five-year-old children group, adolescent group, adult group [14]. Notably, many researchers have been using the indicator of infant mortality rate and the under-five children mortality rate as an instrument to see the degree of environmental policies, pollution, and development of a region [15] [16] [17]. The major countries have already put the goals of decreasing the infant mortality rate and the under-five mortality rate on the Millennium Development Goals (MDGs) to achieve the success of the sustainable development [18]. A paper of Pierce and Schott in 2016 of NBER [19] even conducted the positive correlation between the external economic shock with the suicide rate, also along with the drop of the employment supply. If there could be a study of China combine the development of tourism industry as an external shock with the demographic features, it could answer the questions of how the tourism industry in China impact the environment (as stated by Wang et al. [20], the tourism sector holds a negative effect on the utilities of the residents), human social activities and if the current tourism industry creates negative externalities towards to society. However, a national-wide time series study has not been applied to China to analyze the relationship between the tourism industries and demographic features in China in empirical work.

In this paper, the primary objective is to use the panel data sets of China containing both demographic characteristics and tourism economic indicators to examine the relationship of the two. Moreover, this paper provides the quantitative analysis of the tourism industry to firstly show the scale of this sector of China for further study of the literature. The significant contribution of this study is as follows: first, this article constructs the panel dataset from China Statistical Yearbooks and The Yearbook of China Tourism Statistics and Supple- 
ment. Second, this study analyzes the development of tourism with the demographic features with the quantitative analysis of the degree of the economic scale of that industry.

\section{Data}

The data that this study uses to develop the evaluation of the tourism industry of China in the past decades come from two recourses. First, the data are from the Yearbook of China Tourism Statistics and the supplement of the Yearbook of China Tourism Statistics from 2007 to 2013 published by the National Tourism Administration of the People's Republic of China. The series of the materials fully provides the information of the development of the tourism industry of China yearly and is the good resource for researchers to dig out more behind the phenomenon. Second, this paper uses the China Statistical Yearbook conducted by the National Bureau of Statistics from 2007 to 2013 to construct the demographic related datasets. In the following section, this paper will introduce groups of variables from each dataset for this paper.

\subsection{The Yearbook of China Tourism Statistics and Supplement 2007-2013}

There are two Statistical Yearbooks published by the National Tourism Administration of the People's Republic of China each year to provide the related tourism datasets. From the Yearbook of China Tourism Statistics, this study chooses the panel variables of the income from the international tourists to each province in China from 2007-2013. The reason to choose this variable fit the global trends and characteristic of the development of tourism industry: the increasing trend of tourism trips by international tourists all over the world. From the supplement of the Yearbook of China Tourism Statistics, this study chooses the panel variables related to the economic indicator of two big groups of tourism industry: the star-level hotels and the travel agencies. The first group of variables is the revenues earned by each of the two groups each year by each province. The second group of variables drawn is the profits received by both star-level hotels and travel agencies by province from 2007 to 2013. The third group of the variables is the returns of the total productivity by every province in each year. The fourth group of variables is the average-level of the total labor employment of either star-level hotels or travel agencies each year by province level.

To understand the status of the development of the two big sectors (star-level hotels and travel agencies), this study puts the time series trend of the panel data group in Figure 1. It is very clear in the graph in province level, the development of the tourism industry has not been always promising in China. Beijing, Guangdong and Shanghai always have some positive profits in both star-hotel department and the travel agency sector. However, most of the provinces in China showed some negative of the profits in the development of the tourism industry by their two biggest sectors. It is not easy to distinguish the effect of the 
Profit by Province, 2007-2013

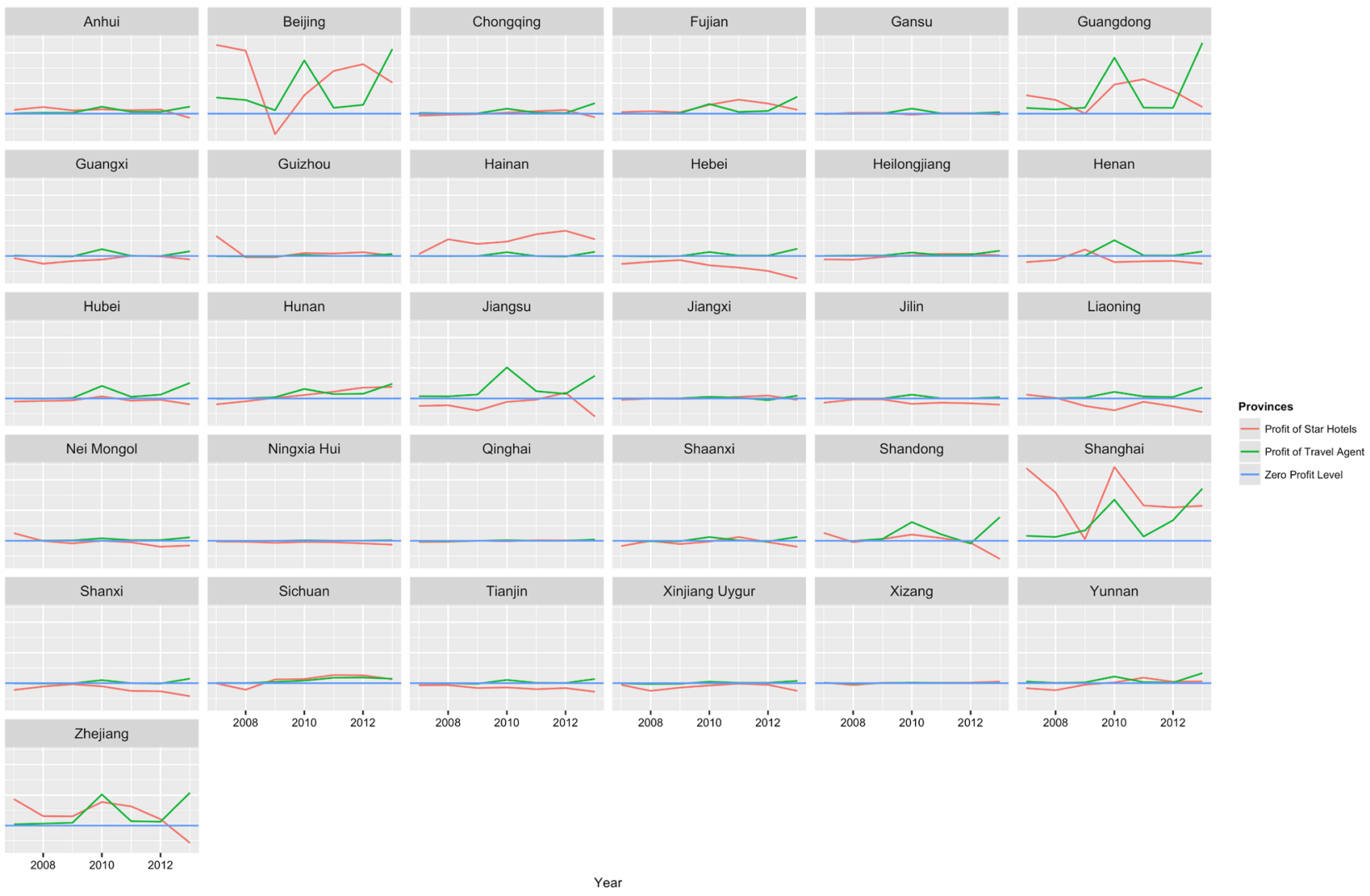

Figure 1. Profits of Star-level Hotels and Travel Agent in Each Province 2007-2013. Note: As shown in the figure, the blue line labels the zero-profit level. From year 2007 to 2013, not every time, every sector of the tourism industry can always bring some positive profits back to that province, except to Beijing, Guangdong and Shanghai.

development of the tourism industry on other fields directly since there exists inconsistency of the trend across the provinces in China in the past few years. To better understand the logic behind these numbers and trends, the economic models need to be applied to give a further analysis.

\subsection{Demographic Features: From China Statistical Yearbook 2007-2013}

From the China Statistical Yearbook, one could obtain the time series variables related to demographic feature by province in China. The chosen variables are: total population by each province, urban population by each province, total fertility rate (per thousand) by each province, mortality rate by each province from 2007 to 2013. From Figure 2 and Figure 3, we can observe the spatial distribution of the total population and urbanization process by province in each year respectively. Furthermore, by the changes of trends in numeric term, this paper puts the time series trend of the ratio of urbanization in each province in Figure 4. As shown in the pictures, the gains of the total population in China in the past few years were not that much, however, the urbanization achieved a steady and an increasing progress by almost every province in China, except for Xizang 


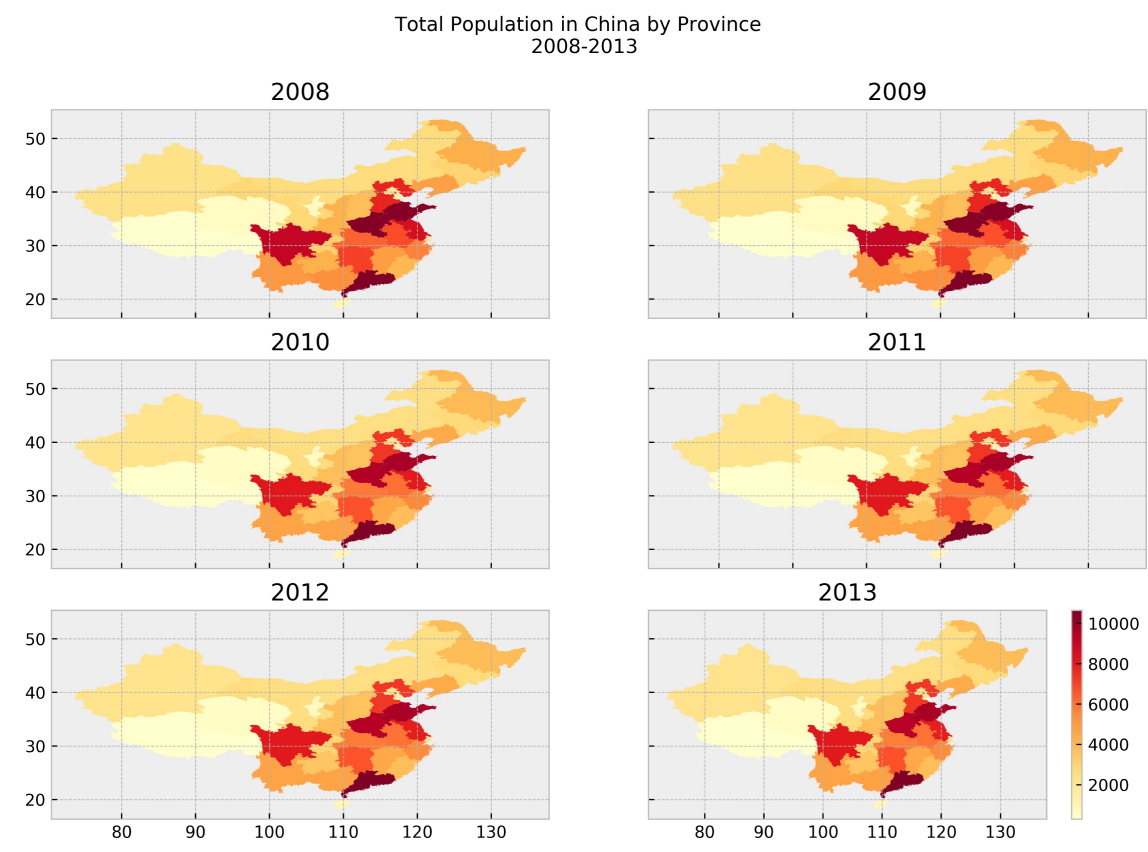

Figure 2. Total Population Spatial Distribution by Each Province in China 2007-2013.

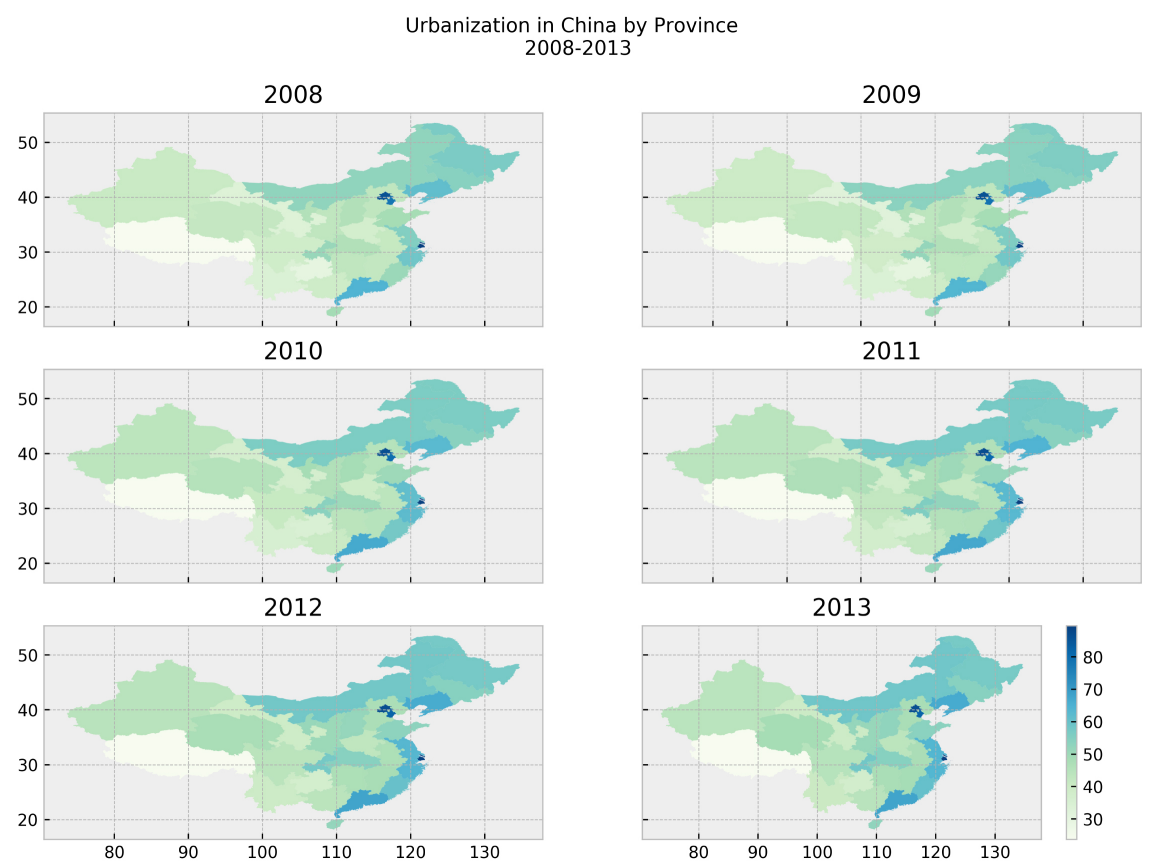

Figure 3. Urbanization Level Spatial Distribution by Each Province in China 2007-2013.

Province. That fits the facts described before. While small changes hold in the total population in China, the urbanization process goes fast in the past years. However, that will leave the puzzle to the problem about the lack of labor supply. The next step is to check the total fertility rate and mortality rate to give the picture of the main demographic picture in China.

In Figure 5, you can find out the total fertility rate and mortality rate of each 


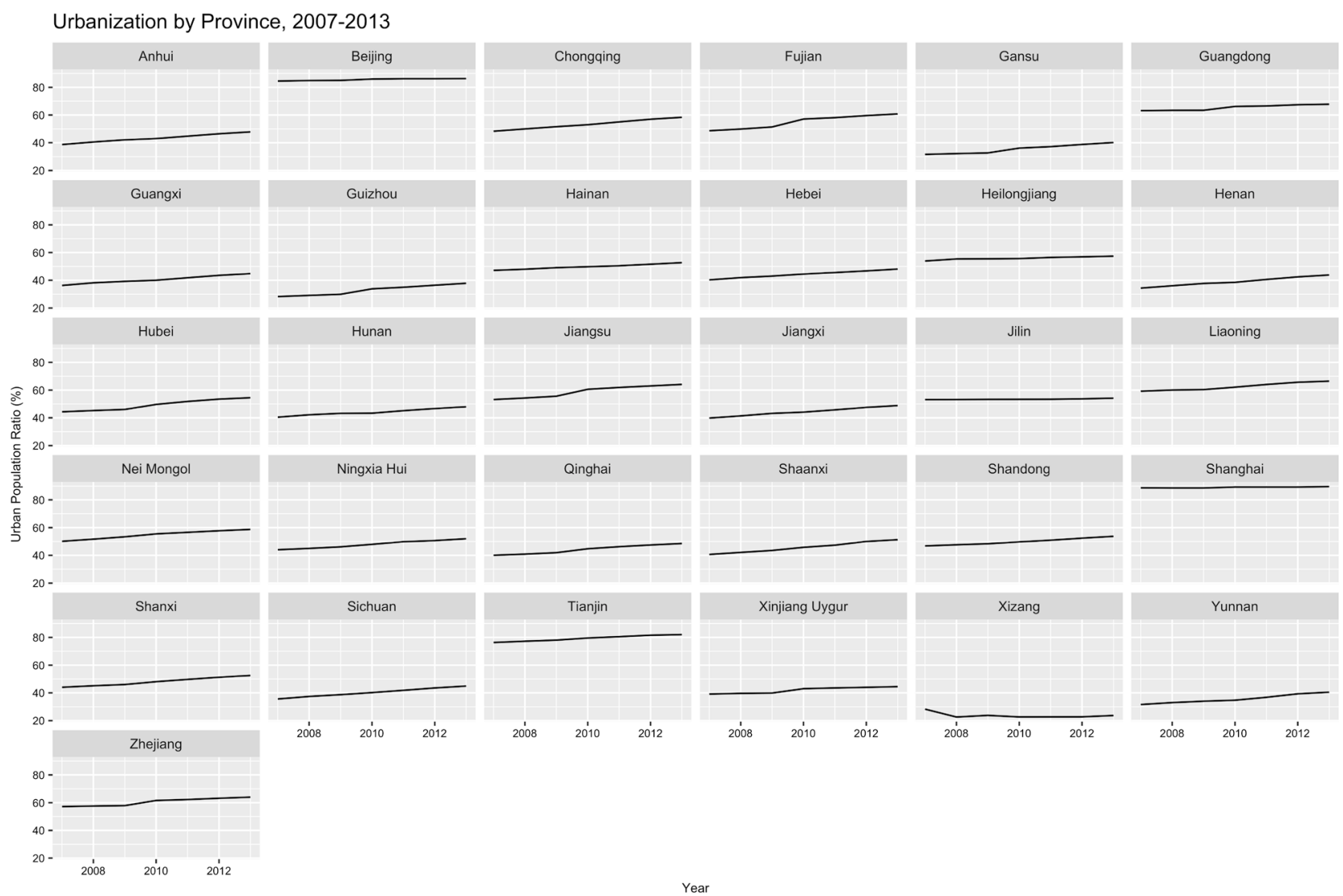

Figure 4. Urbanization Level Ratio Trend by Each Province in China 2007-2013.

province at the same time from 2007 to 2013 . The situations vary hugely from province to province about the changes of the fertility rate, while some provinces steadily hold the decreasing fertility rate (such as Guangdong and Ningxia), but other provinces have been applying the increasing total fertility rate such as $\mathrm{Hu}$ nan and Hubei. These facts will keep adding the ambiguity about the topic we are discussing here: what is the relationship between the development of the tourism and the changes of the features of demographics? Is there any correlation between some of the big aspects of the two groups? If so, how would we evaluate the relationship between the two?

In the next section, a structure model will be set up to reveal how the industry of the tourism developed by itself, that is, is it behaving as a scale economy or not.

\section{Models and Results}

In this section, this paper uses two sub sections to describe the evaluation of the tourism industry in China, and presents the main results coming from each of the models.

\subsection{Scale Economy Quantitative Analysis}

In the theory of Microeconomics, we learned that if an economy holds an 


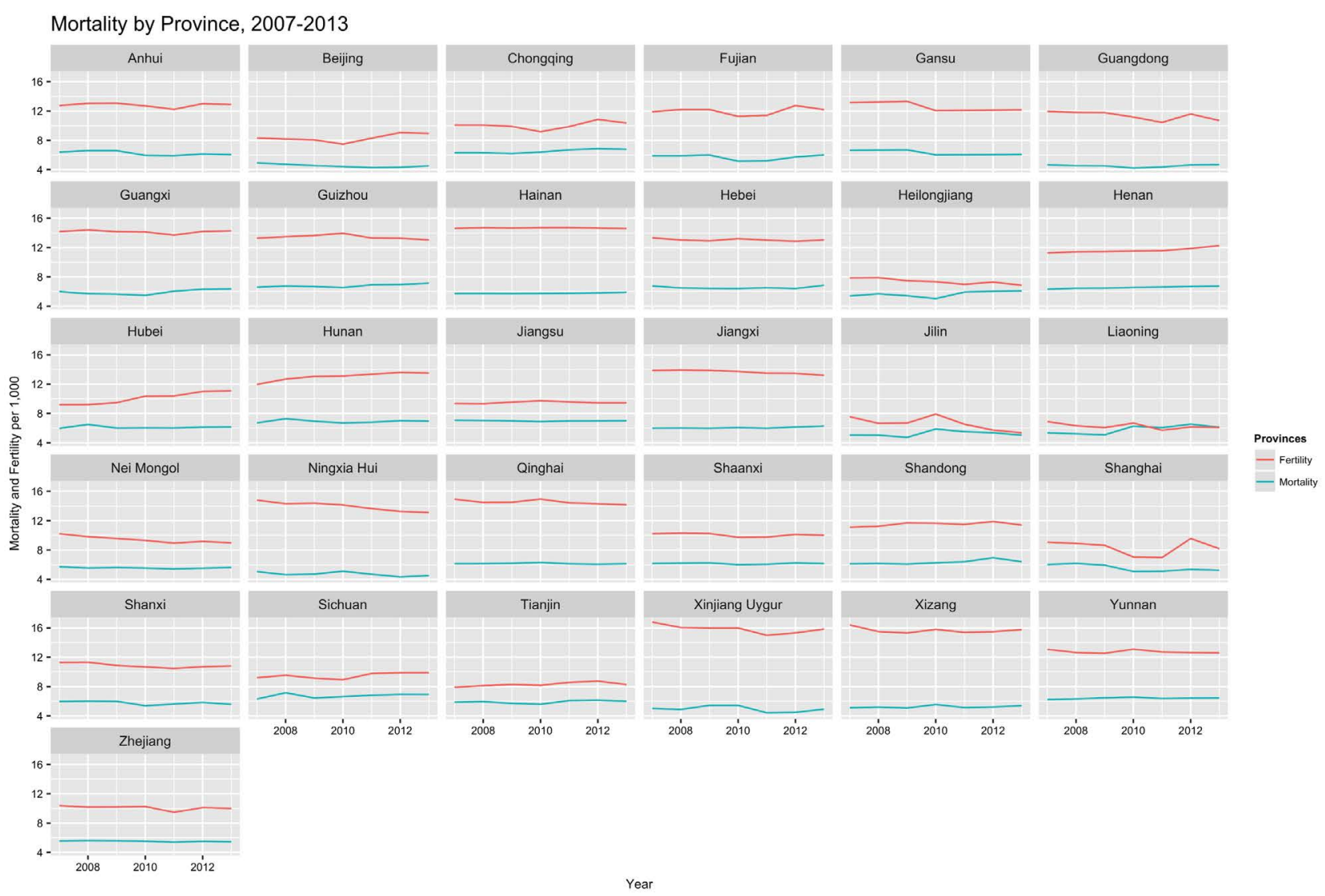

Figure 5. Total Fertility Rate and Mortality Rate by Each Province in China 2007-2013.

increasing return to scale, it must has

$$
\text { input }^{\text {alpha }} * Q\left(\frac{(\text { input })}{\text { input }}\right)>\text { input } * Q \text {. }
$$

In this sense, let us simply assume that the input is labor related (of course) of each of the big sector of tourism industry: star-level hotels and travel agencies. In that sense, with the variable we choose in the Section 3.1, we can start to evaluate if the economy of the tourism industry is increasing scale to economy, decreasing scale to economy or constant scale to economy by checking if the alpha value is greater than 1 , less than 1 or equal to 1 . After divide the returns of the total productivity by the average-level of the total labor employment of either star-level hotels or travel agencies each year by province level respectively, a panel sequence of results are shown in Figure 6 to give the idea about the basic structure of the industry of the tourism in China. However, the results do not show a very exciting news about the efficiency of the tourism industry in China. Except for the beginning of the investigating period (2007-2013) in Shandong Province, and recent development in Hubei Province, the economy scale of both the two sectors in tourism industry behave in a slightly decreasing scale to the economy. Combined with the negative profits from the two sectors as it is observed in the last section, it is not difficult and is reasonable to make a simple 


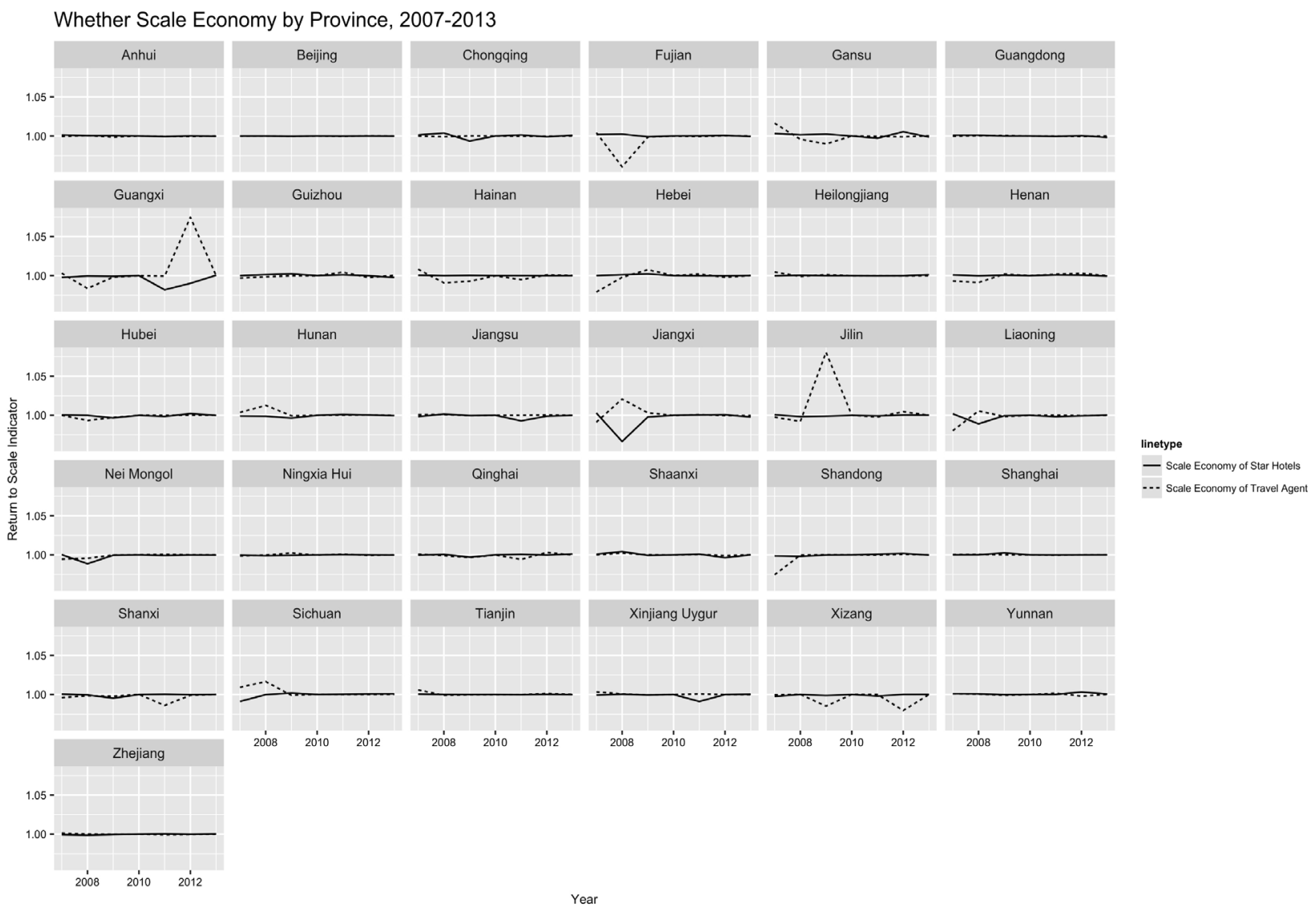

Figure 6. Economic Scale of the Tourism Industry by Each Province in China 2007-2013.

conclusion. The lack of efficiency of the tourism industry is one of the reason why the profits of this industry are not always positive all over the country in the past few years. But to further understanding how this inefficient tourism industry could affect the demographics features, I mean, the urbanization process and the fertility behaviors of residents in China, in the next sub section, the regression models could provide a deeper and cleared view for this evaluation.

\subsection{Regression Models}

To run the regression of the panel data sets, this paper selects the group of linear regression models containing pooled regression model, fixed effect model and random effect model to test the group of variables chosen above respectively for this study. The basic structure of the panel data model is the following:

$$
y_{i t}=\alpha_{i t}+\beta^{T} x_{i t}+u_{i t} .
$$

When $\alpha_{i t}=\alpha_{i}$ without the varies from the time, it is a pooled linear regression model. When we assume that the basic linear model behaves in the following:

$$
y_{i t}=\alpha_{i t}+\beta^{T} x_{i t}+u_{i}+\varepsilon_{i t} .
$$

When $\alpha_{i t}=\alpha_{i}$ for each $t$ and there is correlation between $x_{i t}$ and $u_{i}$, it is a 
fixed model; on the other hand, when $\alpha_{i t} \neq \alpha_{i}$ and there is no correlation between the regressors and the individual specific variable $u_{i}$, it is a random effect model. The Hausman test model is applied between the fixed effect model and the random effect model. The group of the regressions is shown now.

\subsubsection{Fertility V.S. Tourism Development}

The first regression is the pooled regression model, which is

$$
\log (\text { Fertility })_{i t}=\alpha_{i}+\beta_{1} \log (\text { income from international tourists })_{i t}+\varepsilon_{i t}
$$

The results are shown in Table 1. It is shown that the lunit increase on the growth of the income from the international tourists by each region will drop the growth of the local fertility by $6 \%$. The results from the fixed effect model and random effect model do not give a significant value on the regressors, so the conclusion is that the increasing inflows of the outside international tourism will decrease the local fertility rate significantly.

\subsubsection{Mortality VS Tourism Development}

The first regression is the pooled regression model, which is

$$
\text { Mortality }_{i t}=\alpha_{i}+\beta_{1} \log (\text { Revenue_TA })_{i t}+\beta_{2} \log (\text { Productivity_TA })_{i t}+\varepsilon_{i t}
$$

The results are shown in Table 2. It is shown that the 1 unit increase on the growth of the income from revenues of the travel agents will increase the growth of the local mortality by $42.5 \%$, while the 1 unit increase on the growth of the productivity of the travel agents will decrease the growth of the local mortality by $39.5 \%$. While in Table 3, a fixed effect model is applied. Results showed the inverse direction versus the one in Table 2, however, coming from the star-hotel department. The formula is

Mortality $_{i t}=\alpha_{i}+\beta_{1} \log (\text { Revenue_SH })_{i t}+\beta_{2} \log (\text { Productivity_SH })_{i t}+u_{i}+\varepsilon_{i t}(5)$

It is shown that the 1 unit increase on the growth of the income from revenues

Table 1. Fertility VS Tourism [Pooled].

\begin{tabular}{cc}
\hline & Dependent variable: \\
\cline { 2 - 2 } $\log ($ inter_t_inc $)$ & $-0.067^{* * *}$ \\
& $(0.009)$ \\
Constant & $3.127^{* * *}$ \\
& $(0.095)$ \\
Observations & 217 \\
$\mathrm{R}^{2}$ & 0.218 \\
Adjusted $\mathrm{R}^{2}$ & 0.215 \\
F Statistic & $60.003^{* * *}(\mathrm{df}=1 ; 215)$ \\
Note: & ${ }^{*} \mathrm{p}<0.1 ;{ }^{* *} \mathrm{p}<0.05 ; * * * \mathrm{p}<0.01$ \\
\hline
\end{tabular}


Table 2. Mortality VS Tourism [Pooled].

\begin{tabular}{cc}
\hline & Dependent variable: \\
\cline { 2 - 2 } inter_t_inc & Mortality \\
\hline $\log ($ Revenue_ta) & $-0.00000^{* * *}$ \\
& $(0.00000)$ \\
$\log ($ Productivity_ta) & $0.425^{* * *}$ \\
& $(0.061)$ \\
Constant & $-0.395^{* * *}$ \\
& $(0.114)$ \\
& $2.345^{* * *}$ \\
Observations & $(0.557)$ \\
$\mathrm{R}^{2}$ & 217 \\
Adjusted $\mathrm{R}^{2}$ & 0.296 \\
F Statistic & 0.286 \\
Note: & ${ }^{*} \mathrm{p}<0.1 ; * \mathrm{p}<0.05 ; * * \mathrm{p}<0.01$ \\
\end{tabular}

Table 3. Mortality VS Tourism [Fixed].

\begin{tabular}{cc}
\hline & Dependent variable: \\
\cline { 2 - 2 } & Mortality \\
\hline $\log ($ Revenue_sh) & $-0.417^{* * *}$ \\
$\log ($ Productivity_sh $)$ & $(0.148)$ \\
& $0.239^{* * *}$ \\
Observations & $(0.107)$ \\
$\mathrm{R}^{2}$ & 217 \\
Adjusted $\mathrm{R}^{2}$ & 0.042 \\
F Statistic & -0.215 \\
Note. & $4.020^{* * *}(\mathrm{df}=2 ; 184)$ \\
\hline
\end{tabular}

of star-hotel department will drop the growth of the local mortality by $41.7 \%$, while the 1 lunit increase on the growth of the productivity of the star hotel will rise the growth of the local mortality by $23.9 \%$. But the conclusion could be achieved from this result, which means the development of the tourism locally will not always help the drop of the mortality. It could be either increase the pollution of the local environment, or increase the crime rates. A further discussion would be required to develop the study in this direction.

\subsubsection{Urbanization VS Tourism Development}

From the pooled regression model, 


$$
\begin{aligned}
& \text { Urbanization }_{i t}= \alpha_{i}+\beta_{1} \log (\text { Revenue_SH })_{i t}+\beta_{2} \log (\text { Profit_SH })_{i t} \\
&+\beta_{3} \text { inter_t_in } i t \\
&+\varepsilon_{i t}
\end{aligned}
$$

The results are shown in Table 4. It is significantly shown that the 1 unit increase on the growth rate of the revenues, and profit of the star hotels will give a $770 \%$ and $163.3 \%$ grow of the urbanization ratio correspondingly. Similar conclusion would be found in the random effect model, which after the Hausman test gives a p-value of 0.21 that rejects the fixed effect model.

$$
\begin{aligned}
\text { Urbanization }_{i t}= & \alpha_{i t}+\beta_{1} \log (\text { Revenue_SH })_{i t}+\beta_{2} \log (\text { Profit_SH })_{i t} \\
& +\beta_{3} \text { inter_t_in }{ }_{i t}+u_{i}+\varepsilon_{i t}
\end{aligned}
$$

In Table 5, the random effect model tells us the similar results as the pooled one, instead of $700 \%$ and $163.3 \%$ increase on urbanization, the 1 unit increase on the growth rate of the revenues, and profit of the star hotels will give a $414.4 \%$ and $405 \%$ increase. The prominent positive effects demonstrate that the better the development of the local tourism industry, the higher the pace of the urbanization will be generated by the effect of such.

\section{Conclusion}

In this paper, this study analyses the relationship between the tourism industry and the demographic features in China in recent years. In a sum, the results imply that the tourism helps to build a higher urbanized society with more migrant inflows crashing into the urban sectors. However, due to its structure and inefficient productivity, the tourism industry in China has brought adverse effects on the local fertility rate and the mortality rate. The results from the panel

Table 4. Urbanization VS Tourism [Pooled].

\begin{tabular}{cc}
\hline & Dependent variable: \\
\cline { 2 - 2 } & Urban. Ratio \\
\hline inter_t_inc & $-0.00001^{* * *}$ \\
$\log ($ Revenue_sh) & $(0.0000)$ \\
& $7.714^{* * *}$ \\
$\log$ (Profit_sh) & $(1.607)$ \\
& $-1.633^{* * *}$ \\
Constant & $(0.876)$ \\
& $-0.66 .4499^{* * *}$ \\
Observations & $(16.814)$ \\
$\mathrm{R}^{2}$ & 102 \\
Adjusted $\mathrm{R}^{2}$ & 0.616 \\
F Statistic & 0.605 \\
Note: & ${ }^{*} \mathrm{p}<0.1 ; * * \mathrm{p}<0.05 ; * * * \mathrm{p}<0.01$ \\
\hline
\end{tabular}


Table 5. Urbanization VS Tourism [Random].

\begin{tabular}{cc}
\hline & Dependent variable: \\
\cline { 2 - 2 } & Urban. Ratio \\
\hline inter_t_inc & $-0.00001^{* * *}$ \\
$\log ($ Revenue_sh $)$ & $(0.0000)$ \\
& $4.144^{* * *}$ \\
$\log ($ Productivity_sh $)$ & $(1.062)$ \\
& $4.050^{* * *}$ \\
Constant & $(0.884)$ \\
& $-0.14 .302^{* * *}$ \\
Observations & $(12.490)$ \\
$\mathrm{R}^{2}$ & 217 \\
Adjusted $\mathrm{R}^{2}$ & 0.471 \\
F Statistic & 0.463 \\
Note. & $63.109^{* * *}(\mathrm{df}=3 ; 213)$ \\
& $* \mathrm{P}<0.1 ; * * \mathrm{p}<0.05 ; * * \mathrm{p}<0.01$ \\
\hline
\end{tabular}

data linear regression show that the tourism industry in China mostly behaves in a slightly decreasing scale to the economy. Furthermore, the development of the tourism economy, specifically, the inflows of the international tourists negatively correlated with the total fertility rates locally. Third, the growth of the local tourism industry continues to increase some of the mortality rates of some provinces, but highly correlated with the urbanization rate of China in the last few years.

In the previous section, this paper discussed the components of mortality rate. The analysis of mortality rate with the development of the tourism industry in China can be untangled into two major parts. First, the infant or under-five children mortality rate can be related to the tourism sector. Seen from the results, the increasing mortality rate of this baby group implies that this tourism industry sector brought a negative effect on the environment pollution and policies. On the other aspect, the negative effect of the tourism development associated with the increase of the adult mortality rate shows the consistency in the literature: if we consider tourism industry as a shock to the local economy, it would probably have increased the crime rates, pressure to the residents, and in the end increase the mortality rate of that place. This paper also proves that the tourism industry in China in recent years is mostly decreasing returns to scale, which means the productivity of this tourism industry is not efficient. It is also consistent with the results from the empirical regression on the datasets that the negative effect on lower fertility of industry showed a low productivity level of the tourism industry. In one aspect, it is because of the impact of the outsiders on the fertility rate. The increased mobility of the tourists' group gains the diffi- 
culty for the stable of the society, which does not help the decision of the increase of the fertility even under the more relaxed political policy. On the other side, it may cause more pressing issues such as environmental pollution, increasing crime rate due to its decreasing scale to the economy.

Like other empirical studies, this paper inevitably has certain limitations. This paper used the panel data of province-level from 2007-2013 of China to evaluate the development of the tourism industry in China, instead of the most recent data. Because the most recent related dataset from both tourism industry and demographic features are not publicly available yet to construct. But first, the post financial crisis data are applied and the effects of the development of that period are available. Second, the results are consistent with the fact that the low efficiency of the tourism industry indeed impacts negatively on the net growth of the population, but helps accelerate the pace of urbanization in mainland China. Third, with the same methods used in this paper, once the free and publicly available data are published, the results could be generated reproducible of this paper.

Overall, it seems that the current tourism industry does not satisfy the demand of a long-term sustainable development in China. For example, since 2007, the growth of the qualified AAAAA tourism resorts has been developed and later repealed by the government. It is both misleading for the consumer's side and a huge waste of the national resources for the tax payers. Another example comes that recently many tourism resorts have been reported that they treated tourists horribly which brought bad reputation for the tourism and made it difficult to improve [21]. This also explains and fits the results of this paper. It is essential for both the central government and the local government to adjust the structure of the tourism industry. The inefficiency in this sector, will not only impact the environment and generate pollution, but also discourage the human social activities. The more dangerous aspect of this inefficient industry is that it indeed highly associated with the increasing urbanization pace. It is easy for the government and residents to ignore the hidden dangerous side-effect of this inefficient sector, which could delay the development of the economy of China. The government of China must achieve an environment friendly tourism industry to reduce these negative externalities of the society as soon as possible. The long-term sustainable goal must be achieved in a way with less negative externalities of the tourism industry in China. And I hope that not only China, but also other countries should follow a more environment friendly development goal.

\section{References}

[1] World Tourism Organization. (2017) Why Tourism? http://www2.unwto.org/content/why-tourism

[2] China National Tourism Administration. (2018) 2017 Annual Report on Tourism Market and Comprehensive Contribution Data.

http://www.wta-web.org/eng/xwdt_4020/xw_4021/201802/t20180207_856039.shtml 
[3] Ma, T., Hong, T. and Zhang, H. (2015) Tourism Spatial Spillover Effects and Urban Economic Growth. Journal of Business Research, 68, 74-80. https://doi.org/10.1016/j.jbusres.2014.05.005

[4] Zhao, L. and Tang, C.C. (2017) China's Tourism Industry, Industrial Structure and Economic Growth. Resources Science, 39, 1918-1929.

[5] Kim, W., Jun, H.M., Walker, M. and Drane, D. (2015) Evaluating the Perceived Social Impacts of Hosting Large-Scale Sport Tourism Events: Scale Development and Validation. Tourism Management, 48, 21-32. https://doi.org/10.1016/j.tourman.2014.10.015

[6] Desa, U.N. (2013) World Population Prospects: The 2012 Revision. Population Division of the Department of Economic and Social Affairs of the United Nations Secretariat, New York. https://doi.org/10.18356/02911eeb-en

[7] Feng, W., Cai, Y. and Gu, B. (2013) Population, Policy, and Politics: How Will History Judge China's One-Child Policy? Population and Development Review, 38, 115-129. https://doi.org/10.1111/j.1728-4457.2013.00555.x

[8] Hanrahan, M. and Baculinao, E. (2017) China Population Crisis: New Two-Child Policy Fails to Yield Major Gains.

https://www.cnbc.com/2017/01/28/china-population-crisis-new-two-child-policy-fa ils-to-yield-major-gains.html

[9] Smith, K., Backer, E., Baum, T., Benkendorff, P., Butterfield, S., Cothran, C., et al. (2011) Tourism and Demography. Goodfellow Publishers Ltd., Oxford.

[10] Casagrande, M. (2016) Heritage, Tourism, and Demography in the Island City of Venice: Depopulation and Heritagisation. Urban Island Studies, 2, 121-141. https://doi.org/10.20958/uis.2016.6

[11] Verma, R. (2016) Unmade in China: The Hidden Truth about China's Economic Miracle. By Jeremy R. Haft. International Affairs, 92, 754-756. https://doi.org/10.1111/1468-2346.12636

[12] Luo, J.M., Qiu, H. and Lam, C.F. (2016) Urbanization Impacts on Regional Tourism Development: A Case Study in China. Current Issues in Tourism, 19, 282-295. https://doi.org/10.1080/13683500.2015.1033385

[13] Jones, L.E. and Schoonbroodt, A. (2016) Baby Busts and Baby Booms: The Fertility Response to Shocks in Dynastic Model. National Bureau of Economic Research, 22, 157-178. https://doi.org/10.1016/j.red.2016.07.001

[14] United Nations, Department of Economic and Social Affairs, Population Division (2017) World Population Prospects: The 2017 Revision.

https://www.un.org/development/desa/publications/world-population-prospects-th e-2017-revision.html

[15] Foster, A., Gutierrez, E. and Kumar, N. (2009) Voluntary Compliance, Pollution Levels, and Infant Mortality in Mexico. American Economic Review, 99, 191-197. https://doi.org/10.1257/aer.99.2.191

[16] Hanna, R.N. and Oliva, P. (2010) The Impact of Inspections on Plant-Level Air Emissions. The B.E. Journal of Economic Analysis and Policy, 10, 1-33. https://doi.org/10.2202/1935-1682.1971

[17] Greenstone, M. and Hanna, R. (2014) Environmental Regulations, Air and Water Pollution, and Infant Mortality in India. American Economic Review, 104, 3038-3072. https://doi.org/10.1257/aer.104.10.3038

[18] You, D., Hug, L., Ejdemyr, S., Idele, P., Hogan, D., Mathers, C. and Alkema, L. (2015) Global, Regional, and National Levels and Trends in under-5 Mortality be- 
tween 1990 and 2015, with Scenario-Based Projections to 2030: A Systematic Analysis by the UN Inter-agency Group for Child Mortality Estimation. The Lancet, 386, 2275-2286. https://doi.org/10.1016/S0140-6736(15)00120-8

[19] Pierce, J.R. and Schott, P.K. (2016) Trade Liberalization and Mortality: Evidence from US Counties. Finance and Economics Discussion Series, 94, 1-68. https://doi.org/10.3386/w22849

[20] Wang, S. and Chen, J.S. (2015) The Influence of Place Identity on Perceived Tourism Impacts. Annals of Tourism Research, 52, 16-28. https://doi.org/10.1016/j.annals.2015.02.016

[21] China Daily (2018) Snow Town Must Clean up Its Act. http://www.chinadaily.com.cn/cndy/2018-01/17/content_35519291.htm 